Talía. Revista de estudios teatrales ISSN-e: 2659-806X

\title{
El universo onírico de Andrej Zholdak a través de los sueños de Hamlet: Hamlet. Dreams y su paso por el Teatro Español
}

\author{
Marga del Hoyo Ventura*
}

Recibido: 26 de abril de 2018 / Aceptado: 13 de enero de 2019

Resumen. El presente artículo pretende acercarse a la creación escénica y dramatúrgica del director ucraniano Andriy Zholdak a partir del espectáculo Hamlet. Dreams. El complejo universo poético de este director nos enfrenta como espectadores a diversas estrategias que se relacionan con la dramaturgia contemporánea europea. La relación estética entre el texto de Shakespeare y la creación de Zholdak se apoya en la deconstrucción, tanto a nivel fabular como a nivel escénico. Zhodak proyecta su universo propio, su experiencia vital, sus pulsiones creativas, en una complicada pieza dividida en tres partes polisémicas donde el trabajo gestual del actor y el campo sonoro se revelan como los signos escénicos principales.

Se aborda también en este artículo la respuesta de la crítica que el espectáculo tuvo en sus dos únicas exhibiciones en nuestro país, en Madrid y Barcelona, y en Europa, con el objetivo de cotejar la recepción de tan complejo trabajo y su anclaje dentro de las tendencias escénicas europeas del primer tercio del siglo XXI.

Palabras clave: Escenificación contemporánea, dramaturgia contemporánea, deconstrucción, Zholdak, escenificación de textos clásicos

\section{Andrej Zholdak's oneiric universe through Hamlet's dreams. Hamlet. Dreams at the Teatro Español}

\begin{abstract}
The purpose of the present article is to approach the scenic and dramaturgic creation of Ukrainian director Andriy Zholdak starting from the performance Hamlet. Dreams. The complex poetic universe of this director faces us as an audience with a diversity of strategies that are related to the contemporary European dramaturgy. The aesthetic relationship between Shakespeare's text and Zholdak's creation supports itself on deconstruction, both at the fable and the scenic levels. Zhodak projects his very own universe, his vital experience, his creative drive, in a complicated piece divided in three polysemic parts in which the actor's gestural work as well as the sound field reveal themselves as the most significant scenic signs.

This article also addresses the critic's response towards this performance in its two sole exhibitions in our country, in Madrid and Barcelona, and also in Europe, with the purpose of collating or comparing the reception of such a complex piece of work and its anchorage within the European scenic trends of the first third of the $21^{\text {st }}$ century.
\end{abstract}

Key Words: Contemporary staging, contemporary dramaturgy, deconstruction, Zholdak, staging of classic texts

Cómo citar: Del Hoyo Ventura, M. (2019). El universo onírico de Andrej Zholdak a través de los sueños de Hamlet: Hamlet. Dreams y su paso por el Teatro Español, en Talía. Revista de estudios teatrales, 1, 187-198.

* Universidad Internacional de La Rioja. Escuela Superior de Arte Dramático de Castilla y León. ITEM. 


\section{Introducción}

Acercarse al universo escénico y estético de un creador como Andrej Zholdak supone un reto complejo y a la vez apasionante, ya que dicho objetivo conjuga dos características fundamentales para ello: por una parte, la originalidad absoluta de este director, plagada de complejos símbolos y de un sentido absolutamente musical de la escenificación; por otra, la convergencia en él de varias estrategias tanto estéticas como narrativas de elevada complejidad, tales como la deconstrucción, cuestión que analizaremos en las siguientes páginas. El objetivo de este artículo se concreta, pues, en el estudio de la figura de Zholdak como director fundamental en la escena contemporánea europea así como en desentrañar las claves dramatúrgicas y escénicas que plantea en su espectáculo Hamlet.Dreams, sabiendo que tenemos entre manos una complicada pieza de relojería donde la minuciosa técnica se une a la sensibilidad extrema del director.

Cuando me propuse el análisis de esta propuesta escénica a partir de Hamlet, me encontré ante un material complicado: una grabación de más de dos horas de duración, en lengua ucraniana sin subtítulos, con una calidad de filmado relativa. Aún así, el estudio de Hamlet. Dreams consiguió fascinar por su belleza y atraer por la manera en que Zholdak juega con el texto fuente y lo une a numerosas referencias estéticas y culturales, a partir de la herramienta deconstructiva. Gracias a esa investigación, pude conocer el trabajo de este director, relativamente desconocido en España más allá de los círculos de crítica más especializada que pudieron ver Hamlet. Dreams en su rápido paso por el Teatro Español de Madrid -en febrero de 2005-y por el Mercat de Flors de Barcelona -en noviembre de 2004-.

Aunque hace ya algunos años que estas funciones tuvieron lugar, lo que Zholdak dejó en nuestro país fue una forma diferente y novedosa de trabajo sobre los textos clásicos, un juego donde la deconstrucción y la poesía en proporciones iguales lograban fascinar al espectador.

\section{Andriy Zholdak: formación, recorrido y claves estéticas}

Andriy Zholdak nace en Kiev 1962 y, si bien podemos decir que nos hallamos ante un director reconocido por la crítica europea como uno de los más importantes de los últimos años, llama la atención la poca información que de él existe, tanto en internet como en publicaciones. No aparece en las obras teóricas relevantes destinadas a los directores europeos, y si bien en su país es una figura reconocida y polémica a partes iguales, apenas podemos saber de él en el occidente europeo. Encontramos en efecto algunas críticas, no excesivas, sobre su paso por festivales, por la Volksbühne de Berlín, y algunos comentarios que permiten valorar su estancia en los teatros españoles citados. Destacan, en esta labor de investigación, las aportaciones del estudioso británico Noel Witts [Witts 2003] que pueden verse en los archivos virtuales de la Unesco, así como el material crítico y de estudio que se ofrece en la página web oficial del director ${ }^{1}$.

A continuación, trazaremos unas líneas que contextualicen la labor de este creador y nos permitan relacionarlas con Hamlet. Dreams, espectáculo que nos ocu-

Vid. http://svobodazholdaktheatre.com/ 
pa. Todas ellas permitirán comprender mejor las señas de identidad de Zholdak y contextualizar su proceso de maduración como creador. Cabría valorar todo lo que a continuación se refiere desde un discurso en el que no podemos entrar en este artículo, pero que dejamos abierto para posibles reflexiones posteriores, acerca de la evolución de los directores de la antigua Unión Soviética y su relación con las escuelas de dirección de escena rusas y las influencias llegadas desde el occidente europeo. Zholdak, vértice como otros directores, caminará recibiendo influjos tanto de la tradición heredada como del mundo escénico occidental de las últimas décadas del siglo XX y primera del XXI.

Nace Zholdak en una familia de la elite ucraniana vinculada a la literatura y el mundo del cine, influencia fundamental para él. Se familiariza desde joven con la literatura rusa y propia de su país, y de hecho sus primeros trabajos tendrán como base los textos de Chejov (Tres hermanas, 1999, o La gaviota, en 2002) aunque también trabaja otro tipo de obras como Carmen (1996). En 2002 es invitado a dirigir a los actores del teatro de Cherkassy, una pequeña ciudad ucraniana donde escenificó $E l$ casamiento de Gogol. En 2002 estrena Hamlet. Dreams. Ese mismo año había estrenado también Othello?!, en el Teatro Nacional Radu Stanca de Sibiu, en Rumanía, y a partir de 2005 su nombre empieza a verse más allá de su país: Traumspiele, a partir de textos de Strindberg, se estrena en Lucerna; Romeo and Juliet. Fragment es una coproducción entre Ucrania y Alemania a través de la Agencia Cultural Europea; Medea in der Stadt, espectáculo que parte de Eurípides y de Medea material de Heiner Müller, se estrena en la Volksbühne berlinesa. En el año 2006, estrena Phaedra, a partir de Séneca, Eurípides y Racine, en el Teatro de las Naciones de Moscú, y sus trabajos los años posteriores se reparten entre los estrenos en Kharkov y los que lleva a cabo en otros países, destacando su presencia sobre todo en la zona este europea: Rumanía, Finlandia, Rusia, con algunas incursiones en Suiza o Suecia y por supuesto en Alemania.

Las últimas producciones nos acercan a un proceso de relectura de Tres hermanas llamado Behind other side of the curtain, estrenado en San Petersburgo; un montaje sobre la novela Solaris de Stanislaw Lem que ya dirigiera en el cine Tarkovski -director con el que Zholdak está emparentado- coproducido entre el Teatro Nacional de Macedonia y el Wiener Festwochen; o el estreno en Rumanía de Rosmersholm de Ibsen. El año 2018 parece centrado en la dirección de ópera, dirigiendo en Poznan L'elisir d'amore de Donizetti y en San Petersburgo Iolanta de Tchaikovski. A pesar de lo complejo de sus creaciones, y de su moderada difusión, Zholdak ha sido reconocido con numerosos premios, entre los que destacan el concedido a La gaviota en el Festival Internacional de Torun (Polonia), el reconocimiento como mejor director en el Festival de Sibiu (Rumanía) y el Premio UNESCO 2004 a las Artes Escénicas.

Estamos, como se ha indicado, ante un creador internacional cuyos trabajos se circunscriben mayoritariamente a los países del este y Centroeuropa. En España solo hemos podido ver, hasta el momento, Hamlet. Dreams. En cuanto a los autores sobre los que trabaja, se trata de un director que no se vincula a un tipo de textos concretos, ya que en su carrera encontramos desde Shakespeare hasta Heiner Müller, pasando por clásicos griegos, o adaptaciones de Kafka y Dovstoievski. El carácter abierto y poliédrico de sus escenificaciones hace posible y coherente la amplia variación de autores y textos en su desarrollo profesional. El giro hacia la dirección de teatro lírico es una consecuencia clara de la importancia fundamental de la música en las producciones anteriores. 
Zholdak actualmente vive y trabaja en Ucrania, un país con una evolución política y social compleja, marcado por la desintegración de la URSS, el desastre de Chernobil en 1986 y la independencia de Rusia en 1991. Las creaciones vinculadas al Teatro de Kharkov, como Hamlet. Dreams, son fruto del trabajo de un creador en unas muy precarias condiciones, con una determinada concepción del hecho teatral fruto de su educación en la Rusia de aquellos años, y con escasa presencia mediática en el resto de Europa por las circunstancias sociohistóricas de Ucrania y una fuerte censura. A pesar de esto, Hamlet. Dreams es una creación de gran calidad en todos los sentidos, que se exhibe en varios países, y cuyo valor reconocen las críticas de diferentes países, como veremos más adelante.

Pero si bien nunca se pueden olvidar las circunstancias que rodean al creador en su proceso, esto se torna más evidente cuando las circunstancias son complejas desde todas las perspectivas. Nos hemos referido más arriba a la influencia del cine en este director. En efecto, Zholdak estudia cinematografía en la Escuela de Arte de Kiev, y deriva después hacia el teatro, formándose con Anatoli Vassilyev en el GITIS de Moscú durante cuatro años ${ }^{2}$. De él heredó Zholdak la elevada demanda al trabajo de los actores, la necesidad de largos y extenuantes procesos de ensayos y su concepción de lo lúdico y el juego teatral como base de su creación. Su formación procede, pues, de la tradición rusa en la que se forma, a la que se unen las influencias de Pina Bausch o Robert Wilson; todo ello sin olvidar que su universo creador "is also a world created by a member of the post-communist generation in the former Soviet Union, working in a tradition of non-verbal, imagistic theatre with specially trained performers of all ages" [Witts 2003].

Atendamos ahora a su forma de acercarse a las obras, partiendo de una afirmación: Zholdak no monta los textos, sino su particular visión o lectura de ellos unida a una desbordante imaginación y a su particular poética. $\mathrm{Su}$ forma de abordar la construcción dramatúrgica es absolutamente libre, fruto de las diversas influencias mencionadas, y de su trabajo con un elenco altamente formado en el trabajo gestual, así como del peso de su formación cinematográfica y de la importancia primordial que da a la música, convirtiendo el campo sonoro en uno de los elementos principales de sus escenificaciones.

El objetivo de Zholdak no es construir una acción que pueda seguirse a partir de la ordenación escénica, sino crear una recepción activa del espectador a partir de rupturas de la acción y de la amplitud semántica de los signos, así como de una serie de ideas o motivos que desarrolla y concreta solo hasta cierto límite. Por ejemplo, en relación a su montaje a partir de Un mes en el campo de Turguénev, señala: "You watch, not to follow the story, but to follow the series of sometimes connected, sometimes disconnected, images where the physical playing of the actors becomes the essence of the audience experience" [Witts 2003]. Las raíces de esta poética escénica podemos remontarlas, quizá, hasta las aportaciones de la abstracción en el teatro, en tanto que no se atiende a la construcción de la fábula como elemento fundamental del espectáculo sino al estímulo permanente, desde lo sensorial, del receptor.

En su búsqueda de estas formas nuevas donde la experiencia del espectador es fundamental, Zholdak llega a replantearse la participación de este en el espectáculo

2 La información sobre Zholdak ha sido extraída de los estudios de Noel Witts citados, de la página web que recopila todo el material personal y creativo de él (svobodazholdaktheatre.com), así como de la ayuda prestada por Katia Zholdak, hermana del director, durante el proceso de investigación. 
y a reformular prácticamente la idea de escenificación, buscando una comunicación con el público donde incluso se pueda entrar y salir de la sala, o acceder al espectáculo en diversos días, porque "a spectator who has bought a ticket for the play can visit its diferent parts during the month" [Witts 2003]. En el caso de Hamlet. Dreams no se llega a ese extremo, pero sí hay una concepción nueva del hecho escénico que tiene más que ver con su aproximación a lo que hoy podemos llamar realización escénica por contraste al concepto de puesta en escena. Estamos, pues, ante un creador escindido entre la tradición heredada y el ansia de reforma en un país donde ni las circunstancias políticas ni las económicas han permitido un desarrollo deseable del hecho escénico. La convivencia de ambas formas, la tradicional y la innovadora, se unen con un sentido claramente irónico en Hamlet. Dreams, como veremos más adelante.

En esa particular concepción del hecho escénico juegan un papel fundamental los actores: el trabajo de Zholdak con ellos es durísimo. Desea que el actor sea la base de la escenificación, y le pide que no trate de calcar la vida en el arte, ni mucho menos. Porque para él el actor debe estar en el escenario de manera muy diferente a como está en la existencia real. Lejos de ser una inconcreta fantasía, lo que Zholdak propone es una poética más cercana a Barba, Artaud y Grotowski que a la tradición del realismo ruso.

En una extensa carta llamada Letter to the directors and actors, not yet born, así como en otros artículos recogidos en su página $\mathrm{web}^{3}$, podemos valorar la relación de Zholdak con el actor, a quien necesita como eje de su poética, pero de quien tiene una compleja opinión sobre su autonomía, su aportación creativa y su capacidad de sacrificio extremo. Esta carta tiene mucho de irónico, y subraya esa faceta permanentemente lúdica y provocadora del director. Para Zholdak el actor se mueve en la lucha continua entre el humano y el robot, como indica en Actor. The robot. The struggle between the human-actor and actor-robot, en la página web citada.

\section{Las claves dramatúrgicas y escénicas de Hamlet. Dreams}

Vayamos ahora a Hamlet. Dreams ${ }^{4}$. Estamos ante un espectáculo que no dudamos en concebir como realización escénica, aceptando como tal la definición que Erika Fischer-Lichte [2011] desarrolla al respecto, y con la que se refiere a una serie de espectáculos que se hallan a medio camino entre lo performativo y lo representacional. Esto es comprobable si valoramos que en Hamlet. Dreams Zholdak no quiere hacernos llegar la peripecia de Hamlet, ni siquiera a partir de su lectura propia, ni construye unos personajes para ello. Zholdak mantiene la presencia fenoménica del actor, en tanto que este no es siempre portador de un constructo imaginario que se sitúe en unas coordenadas de conflicto determinadas. Prima el cuerpo, la acción que este realiza en el aquí y ahora, la inclusión en un grupo que realiza una acción colectiva, o incluso la sensación que el cuerpo del actor genera desde el estatismo y la relación con el campo sonoro y lumínico. Podríamos decir que se avanza aquí

\footnotetext{
Vid. http://svobodazholdaktheatre.com/en/news/1544645347

$4 \quad$ El análisis del espectáculo está realizado a través de una grabación facilitada por el Dr. López Antuñano. En el Centro de Documentación Teatral se conserva una copia que presenta el montaje según el orden que pudo verse en España, y que no corresponde exactamente al visionado realizado para esta investigación.
} 
hacia una nueva concepción de personaje dramático, que no se apoya en la individualidad de este sino que presenta la realización de acciones físicas concretas con el fin de crear una determinada atmósfera y aportar una serie de significados desde el reconocimiento -no siempre exacto- de esas acciones. Como señala Lehmann a propósito del postdramatismo, "el cuerpo se convierte en el centro no como portador de sentido, sino en su physis y gesticulación" [2013: 165].

A ello se suma una delgada línea de acción que puede relacionarse con el texto fuente de Shakespeare, o no 5 . Porque no es la fábula conocida por todos la que Zholdak construye en el escenario sino que a ella se suman una serie de motivos temáti$\cos ^{6}$ [Marchese y Forradellas 1986: 274-275] que se desarrollan en mayor o menor medida, y que permiten lo que podríamos llamar líneas de fuga que abren multitud de significados posibles.

Ante semejante construcción escénica, debemos escoger una forma de análisis acorde con el objeto de estudio, y es precisamente ahí donde resulta pertinente detenernos en los núcleos o motivos temáticos como ejes de la acción que ocurre en la escena. Tras el estudio de la totalidad de fragmentos que componen Hamlet. Dreams, hemos elaborado una posible lista que recoge las ideas recurrentes en la escenificación:

1. La separación de lo masculino y lo femenino, y a la vez la neutralización de la sexualidad: Zholdak presenta a los actores con elementos que neutralizan sus rasgos físicos sexuales: faldas en los hombres-pájaros, pecho tapado tanto en hombres como en mujeres. Por el contrario, los actores que reconocemos como Hamlet, Ophelia, Gertrude, Polonius y Claudius -que no siempre los reconocemos con claridad y no siempre representan esos personajes, salvo Hamlet que no varía-, no desdibujan su sexualidad, sino que mantienen físicamente la identificación con lo masculino o lo femenino.

Desde los motivos que analizamos aquí valoramos esto como una de las claves semánticas, que se puede relacionar con la separación Hamlet / Ophelia impuesta por los personajes mayores, acción que vemos también en algunas secuencias y que remite inevitablemente al texto fuente. El hecho de apuntar un motivo (= separación de hombres y mujeres) y su opuesto (= disolucion de rasgos sexuales en muchas secuencias) constituye una importante seña de identidad de este espectáculo y una estrategia de narrativa escénica coherente con el objetivo de la escenificación.

2. La violencia como fin inevitable en los comportamientos humanos: en_algunas secuencias vemos cómo una serie de acciones que comienzan de manera lúdica acaban con la aniquilación de unos personajes por otros. Del mismo modo que en el motivo anterior hemos resaltado la yuxtaposición de dos ideas en principio contrarias, en este caso esas escenas con fin violento tendrían su opuesto en otras que concluyen con una idea de celebración, de fiesta, de unión de todos los personajes. La violencia y la fiesta, lo agresivo y el júbilo, lo lúdico y la aniquilación: todo ello forma parte del mundo escénico que Zholdak configura.

\footnotetext{
5 Aclaramos que el espectáculo se compone de tres bloques, cada uno formado por multitud de escenas de diversa duración. Era el propio Zholdak quien decidía el orden en que los bloques se exhibían en cada país, en función de sus valoraciones de la posible recepción.

6 Utilizamos el término motivo en la acepción que le dan los autores citados: "motivo como unidad significativa mínima del texto (...), motivo como elemento germinal $[y]$ recurrente".
} 
3. La limpieza y la purificación: a partir de objetos escénicos como cubos, agua, jabón o espuma se construye este motivo que destacamos como uno de los principales. La idea de limpieza y pureza se desprende también del actor Hamlet, de Ophelia y de las niñas-ángeles. En el caso de Hamlet es muy evidente, porque a nuestros ojos se configura como un dios antiguo, casi desnudo, blanco, con un trabajo gestual en muchas escenas basado en un caminado lento, armónico, que lo distingue de los demás actores. Ophelia en algunas secuencias aparece igualmente con algo de sobrenatural, por encima de la fisicidad del resto de actores. Las niñas, por su parte, si bien una va de negro y otra de blanco, se relacionan con la pureza en tanto que esta se vincula con la infancia. Las vemos jugar, bailar, reír, ayudar a Hamlet y Ophelia a unirse. Los cuatro constituyen esa idea de blancura y limpieza frente a acciones mucho más contundentes o agresivas y frente a la configuración misma de ciertos personajes.

4. La parcialidad de la mirada: esta idea se desarrolla en uno de los bloques, concretamente en el que en España pudimos ver en primer lugar. En él, unos paneles modulares situados en proscenio obstaculizan la mirada total del espectador sobre las acciones, seleccionando así qué se ve claramente y qué no; o restando a la mirada partes concretas de los cuerpos de los actores a partir del juego de los paneles en el eje horizontal. Vemos además como algunas secuencias están construidas desde la idea de la fotografía: imágenes estáticas sobre las que se oye un click y un arrastre de carrete fotográfico. Con esta propuesta narrativa el director parece insistir en que siempre se elige una mirada, un punto de vista sobre todo, de tal manera que nada es certero absolutamente, sino que la subjetividad y la parcialidad condicionan el posicionamiento del hombre, incluso en el concreto de esta escenificación.

5. La no interrupción de la vida con la muerte: dos acciones muy concretas parece que sustentan este motivo; por una parte, la secuencia de la muerte de Ophelia; por otra, la escena final, situada en una estética y atmósfera de 1900. Ophelia, cuya escena de la muerte reconocemos con relativa facilidad, vuelve a aparecer en escena, lo que no nos sorprende porque ya hemos aprendido como espectadores que el orden de las escenas no construye una fábula lineal. Lo mismo ocurre en la escena final, donde un personaje cae muerto mientras baila: la vida sigue, el baile continúa.

6. El ansia de libertad: hay ciertos signos escénicos que parecen hacernos llegar la idea de libertad: el canto de los pájaros que suena de manera casi permanente, las plumas que llenan el espacio como pequeñas alas voladoras, los hombres pájaro... frente a ellos, la amputación de esa libertad la podemos ver en algunas secuencias, tales como la que nos muestra a los personajes impedidos en su movilidad a partir de una especie de arnés que limita sus desplazamientos, o aquellas centradas en mostrar la rigidez de las partituras gestuales impuestas por otro personaje que sígnicamente enlaza con la idea del poder a partir de batutas, bastones de mando o uniformes militares. Pero sobre todo hay una identificación del personaje de Hamlet con un pájaro, y a la vez con su opuesto lo vemos como pájaro disecado- en un mundo de trinos, plumas, olas de mar... que es también un mundo de hombres detectives, de movimientos pautados, de personajes poderosos que parecen castrar a los demás. 
7. El espionaje, el ocultamiento: a lo largo de la función vemos que los personajes se espían: ocultos tras los paneles móviles, se descubren a veces para esconderse después. No es un motivo que quede especialmente claro, pero sí hay varias secuencias construidas con el juego del espionaje de unos sobre otros.

Hasta aquí los motivos que hemos considerado más relevantes a partir de nuestra recepción y nuestro análisis; somos conscientes de que al intentar encerrarlos en un epígrafe se podría disminuir en parte esa recepción sinestésica esencial para el director y rasgo fundamental de su poética. Pero como hemos indicado al comienzo del listado de posibles temas, ante textos de construcción tan compleja una buena herramienta de análisis puede ser la agrupación de las escenas / secuencias en grupos en los que se desarrollen escénicamente temas semánticamente afines.

No obstante el listado que hemos propuesto no es en absoluto una ordenación ni una jerarquía. En Hamlet. Dreams los posibles temas no se relacionan entre sí desde la ordenación, ni resulta posible, desde la recepción, establecer vínculos con uno de los temas por encima de los demás. Estamos en efecto ante otro de los rasgos del texto posdramático: la desjerarquización o parataxis, es decir, la igualdad en la ordenación de temas que invalida la idea de que una escenificación debe plantear un tema como principal y el creador debe posicionarse ante ese tema desde diversas estrategias. Esa intención permite ampliar lógicamente la semántica del espectáculo, que se abre en multitud de posibilidades sin cerrar ninguna de ellas.

Ya se ha indicado, en coherencia con esta construcción abierta y polisémica, cómo Zholdak divide Hamlet. Dreams en tres bloques que permuta y ordena según sus preferencias, logrando que en cada teatro o en cada país el orden pueda ser diferente ${ }^{7}$. Al tener esta posibilidad de cambio de posición entre las escenas, los posibles significados del espectáculo pueden modificarse, ya que no es lo mismo un bloque situado al inicio de la escenificación que al final de ella. Esta estrategia permite hablar de otra de las características de Hamlet. Dreams, la ateleología o ausencia de final. Con ello, el director se posiciona de nuevo en un planteamiento alejado de lo fabular, el espectáculo se reafirma en su esencia de realización escénica y la polisemia y la ambigüedad aumenta. La capacidad del espectador para semantizar lo que recibe depende fundamentalmente de su subjetividad, de su capacidad para recibir desde la sinestesia más que desde la comprensión racional, y de su vínculo o conocimiento del texto fuente.

Porque con todo lo que hasta aquí se ha referido ¿cuánto queda en este trabajo de Hamlet de Shakespeare? ¿Es posible seguir la huella de un texto cuando el escenario nos presenta un proceso de deconstrucción tan audaz? La respuesta es que sí, siempre que comprendamos que Hamlet es solo un pretexto para jugar con la creación y no esperemos hallar en este montaje una lectura nueva sobre el príncipe danés, o al menos no solo eso. Zholdak utiliza un signo fundamental para tejer la conexión con el texto de Shakespeare: durante todo el montaje escuchamos de manera repetitiva una voz que, desde la lejanía, llama a Hamlet. Ese eco, esa resonancia que dejamos de oír y que se pierde en muchos momentos bajo la presencia absoluta del campo

Lo que en su estreno en Khárkov aparece como bloque tercero -que fue el primero en las representaciones españolas- supone sin lugar a dudas una ruptura estética con el resto del espectáculo. Se conciben varias escenas de ambiente chejoviano sin texto, entre las que deambula el personaje de Hamlet. El manierismo con que el que están concebidas no puede analizarse sino como guiño irónico del director a la tradición escénica heredada y al contraste entre las formas estéticas a las que él como creador se enfrenta. 
sonoro, nos remite a un deseo, una búsqueda, una llamada, en fin, que parece querer conectar con Hamlet más allá de los sueños en los que se halla. Esa voz recurrente es sin duda uno de los pilares de relación con el texto fuente.

Otra de las estrategias de Zholdak para no romper ese cordón con la matriz es que el actor que hace el personaje principal no varía: se mantiene durante los tres bloques de manera semejante, casi por encima del resto, siendo a ratos espectador de las acciones.

Además, hay ciertas acciones que suceden en el texto fuente que podemos reconocer con relativa facilidad -aceptando, por supuesto, el carácter libérrimo con el que están mostradas-: la actuación de los cómicos, la muerte de Ophelia, la actitud tiránica de Polonius y Claudius, o la idea de espionaje y vigilancia que impregna tanto el texto de Shakespeare como el montaje analizado. Como vemos, es posible afirmar que Hamlet está, si bien no como presencia única, y filtrado a partir de los sueños que el título anuncia. Y en ese mundo onírico, la libertad es absoluta.

Vemos, pues, que la técnica de construcción escénica y dramatúrgica de Zholdak es semejante a un collage, una yuxtaposición de escenas, de diversa duración, donde encontramos estos sueños, en las que a veces reconocemos una recreación de acciones del texto fuente, siempre conviviendo con multitud de escenas que no podemos relacionar él y que abren caminos múltiples sobre posibles significados, caminos que son interrumpidos después. Podríamos aventurar que estamos ante una estructura construida desde los que podemos denominar rizoma, en tanto que hallamos en ella posibilidad de relaciones diversas entre las partes, bifurcaciones semánticas y sígnicas sobre las que se vuelve en ocasiones y que con múltiples líneas de fuga buscan, como las raíces de las plantas, abrir -aparentemente- infinitas vías.

Parataxis, rizoma, sinestesia: Hamlet. Dreams es un espectáculo que reconocemos integrante del teatro posmoderno, basándonos en las características que Lehmann señala para estos, tales como ambigüedad, elogio del arte como ficción, discontinuidad, antitextualidad, diversidad de códigos, el actor como tema y figura principal, el texto solo como material de base, deconstrucción, antimimetismo... Es decir, se trata de subrayar la condición de acontecimiento en el aquí y ahora de la representación, sin llegar, en todo caso, a la performatividad ni dejar lugar a un todo vale semántico amparándose en la complejidad deconstructiva.

Porque a pesar de esta apertura absoluta en la dramaturgia y en la escenificación, la estructura no es aleatoria, ni improvisada, ni casual. Sea cual sea el orden de los bloques que conforman el espectáculo, Hamlet. Dreams aparece ante nuestros sentidos como un trabajo extraordinariamente compacto. Solo debemos ser coherentes en nuestra recepción y aceptar el pacto lúdico, que no absurdo, que Zholdak nos propone, dejando que las correspondencias, en el sentido baudelaireano del término, sean la base de la recepción. Como indica Lehmann, la construcción alejada de la contigüidad lleva al descubrimiento de correspondencias, en el sentido, que "describe adecuadamente la nueva percepción del teatro más allá del drama como poema escénico" [Lehmann 2013: 147].

\section{Hamlet. Dreams ante la crítica}

Hamlet. Dreams pudo verse, tras su estreno en Kharkov en 2002, en diversos festivales internacionales: Varna, Moldava, Sibiu, Grenoble, Gdansk y Groningen. En Es- 
paña se programó tanto en el Teatro Español de Madrid en febrero de 2005, como en el Mercat de les Flors de Barcelona, dentro del Festival de Teatre Visual i de Titelles a finales de 2004, como se ha indicado al comienzo de este artículo. El espectáculo tuvo en ambas ciudades un importante éxito, y es muy bien valorado por la crítica teatral:

Escenas independientes de gran plasticidad y enorme poder visual. Escenas bellísimas, sugerentes, de clara atmósfera cinematográfica. Escenas potentes que aprovechan al máximo el espacio y las simples estructuras escenográficas que lo delimitan [...] Las lecturas se multiplican con cada nueva imagen, todas ellas apoyadas por una estupenda banda sonora, uno de los puntales del montaje, en la que está incluido el poco texto que las acompaña [Barrena 2004: 46].

Es este un Hamlet deliberadamente ajeno a Shakespeare, de quien se usan apenas diez folios en sonido pregrabado y que para la ocasión fue traducido al catalán en voz en off. Señalamos lo de grabado ya que el texto ucraniano es, a la postre, una parte más de una sensorial banda sonora en la que cabe la música dance, las melodías de cine, la new age, el sinfonismo y algo de músicas autóctonas de Ucrania (...) En el segundo acto, Zholdak se explaya en un teatro-danza que unos situarán en la órbita de Pina Bausch, otros de Marthaler o de DV8 y que probablemente tenga algo de todos y mucho de ninguno [Fondevila 2004:46].

En Barcelona, además, el montaje de Zholdak se conectó, desde la recepción, con el momento político que estaba viviendo Ucrania:

[Hamlet.Dreams] ha estat a càrrec d'un grup ucraïnes, una compañía molt compromesa políticament que està vivint des de la distancia la crisi interna del seu país. S'anunciava como una de les cites estel-lars d'aquest XVI Festival de Teatre Visual i de Titelles: l'actuació d'una compañía ucraïnesa, a les ordres d'Andriy Zholdak, un director que se'l rifen a mitja Europa i que se l'equipara amb creadors artístics del prestigi de Pina Bausch o Bob Wilson. Però [...] la compañía estaba enormement inquieta per les noticies que arriben d'Ucraïna i el seu director, molt vinculat al partir de l'oposició, no va voler ni fer declaracions publiques a l'espera de què passarà i de si podrá tornar al seu país [ccma.cat $2004^{8}$ ].

El estudioso López-Antuñano aporta además cuestiones claves sobre la construcción de Zholdak y la recepción del espectáculo, cotejada en varios países en los que se exhibe el montaje:

Creo que la respuesta se encuentra en la intención de ofrecer una historia desligada de criterios de racionalidad, que busca percutir en la emoción del espectador, a fin de sobrepasar [las] constrictoras capas culturales. Para conseguirlo, el director acude a juegos ingenuos e infantiles y a una perspectiva irónica, para presentar muchas de las situaciones propuestas [...] De este modo consigue entretener, jugar, provocar y conectar con el público. [...] [Este] tributó una calurosa ovación

Vid. http://www.ccma.cat/324/linstitut-del-teatre-organitza-el-festival-de-teatre-visual-i-de-titelles/noti$\mathrm{cia} / 79892 /$ 
al finalizar cada acto con algunas claras manifestaciones de adhesión. Fue una reacción emocional; sin embargo, cabe dejar planteadas algunas preguntas: ¿basta con el impacto emocional? ¿Se requieren algunos conocimientos previos para descodificar la propuesta escénica y comprenderla? ¿Es necesario este proceso para que las sugerentes imágenes sean algo más que un juego? [López-Antuñano 2004: 185].

La crítica es positiva también en otros países, donde se ve una alta valoración del trabajo de este director, si bien algunas reflejan el estupor tanto de la audiencia como del crítico":

I actually have understood nothig [...] Why [...] one woman in Hamlet does to itself a wine injection, and the second rushes with chloroform and immobilizes people on a scene [...] Why Ophelia falls, jumps up and again falls, as in a attack [...] Simply theatre, and on a broader scale art is an emotion, and at cranky harkovchanina there is a gift to pass emotion directly passing logic, directly in soul [rusnewsjournal.com s. $\mathrm{f}^{10}$.

Zholdak's Hamlet.Dreams, his two-hour take on Hamlet, is a highly charged and energetic piece, with much ensemble movement [...] Once again we have a succession of images, loosely connected with the play, a minimum of text, much frantic music, portraying a decadent court, where sexuality is often uncertainly, and the acting has great physical power. The movement, also highly choreographed, falls somewhere between mime and dance [...] The piece itself is a cheerful two-hour reflection on some of the themes from Shakespeare's play [zagrebtheatrefestival 2013].

Desde Hamlet. Dreams no hemos vuelto a disfrutar de las escenificaciones de Zholdak en España. Hubiera sido una magnífica excusa para seguir profundizando en el complejo y largo debate acerca de la intervención textual en obras clásicas. Zholdak permitió al público español acercarse a una forma diferente y poco habitual de abordar este tipo de trabajos, y dejó ver un ejemplo perfecto de deconstrucción escénica y textual. Conjugó su poética personal con la tradición heredada, de la que parece distanciarle una mirada crítica. Mostró el exhaustivo trabajo de 34 intérpretes en un espacio sencillo, sin grandes medios. Todo ello para llevarnos, desde las claves más estrictas del posdramatismo y desde su extremada sensibilidad artística, a esos sueños de Hamlet y mostrarnos los rincones más escondidos y privados a los que llegó a partir de él.

\section{Bibliografía}

Anónimo: “Русский новостной журнал”, Recurso web <http://rusnewsjournal. com/1/545194/>, Fecha de consulta: 4-XII-2017.

\footnotetext{
9 La página web que recoge el trabajo de Zholdak incluye una sección con críticas internacionales de diferentes espectáculos, así como el trabajo del estudioso Noel Witts.

10 Vid. http://rusnewjournal.com/1/545194/
} 
Anónimo: "Hamlet. Dreams", recurso web <http://www.zagrebtheatrefestival.hr/2004_site/ ephamlet.htm>, Fecha de consulta: 4-XII-2017.

Anónimo: "L'Institut del Teatre organitza el Festival de Teatre Visual i de Titelles", Recurso web <http://www.ccma.cat/324/linstitut-del-teatre-organitza-el-festival-de-teatre-visuali-de-titelles/noticia/79892/>, Fecha de consulta: 4-XII-2017.

Barrena, Begoña (2004): "Inagotable Hamlet", El País, Recurso web: https://elpais.com/ diario/2008/12/21/catalunya/1229825251_850215.html, Fecha de consulta: 4-XII-2017.

Fischer-Lichte, Erika (2011): Estética de lo performativo, Madrid, Abada.

Fondevila, Santiago (2004): "La bomba creativa ucraniana", La Vanguardia, 26 de noviembre de 2004, 46.

Lehmann, Hans-Thies (2013): Teatro posdramático, Murcia, Cendeac.

López-Antuñano, José G. (2004): "El lenguaje teatral de Andriy Zholdak", en ADE Teatro, 102: 183-187.

Marchese, Angelo y Joaquín Forradellas (1986): Diccionario de retórica, crítica y terminología literaria, Barcelona, Ariel.

Witts, Noel (2003): Andriy Zholdak: priest or madman?, Recuro web <https://www.pdffiller. com/81195527--ANDREY-ZHOLDAK-PRIEST-OR-MADMAN-Noel-Witts-Unesco->, Fecha de consulta 4-XII-2017. 